\title{
REDUÇÕES NAS HORAS TRABALHADAS COM COMPENSAÇÃO GOVERNAMENTAL COMO POLÍTICA DE MANUTENÇÃO DO EMPREGO E DA RENDA'
}

Mauricio Cortez Reis²

Joana Simões de Melo Costa ${ }^{3}$

\section{INTRODUÇÃO}

Medidas de manutenção do emprego e da renda dos trabalhadores têm sido adotadas por diversos países como forma de enfrentar a crise provocada pela pandemia da Covid-19. Uma dessas medidas é o programa conhecido como work-sharing ou short-time work, em que o governo oferece subsídios ao emprego em tempo parcial. Com a redução das atividades durante períodos recessivos, o programa tem o objetivo de evitar demissóes por meio de compensaçôes governamentais para reduçóes nas horas trabalhadas pelos empregados.

A redução da jornada de trabalho, ao permitir que as empresas diminuam temporariamente seus custos, pode permitir a manutençáo de postos de trabalho. Evidências apresentadas por Giupponi e Landais (2018) mostram que a redução da jornada de trabalho com subsídio salarial tem efeitos importantes para mitigar a destruição de empregos durante períodos de crise. Além disso, esses mecanismos são relevantes para garantir a renda dos trabalhadores. A manutenção dos vínculos de trabalho também pode ser importante para evitar os custos associados à procura de emprego e à busca por trabalhadores, facilitando a retomada da atividade econômica após a crise (Gerard, Imbert e Orkin, 2020).

Medidas desse tipo foram adotadas em vários países da Organização para Cooperação e Desenvolvimento Econômico (OCDE) durante a crise financeira de 2008-2009, como mostram Hijzen e Venn (2011). A Organização Internacional do Trabalho (OIT) tem recomendado a adoção de políticas de short-time work, enfatizando a sua capacidade de permitir que as empresas retomem as suas atividades mais facilmente quando as restriçôes resultantes da crise da Covid-19 forem amenizadas (ILO, 2020). Essa organização destaca, porém, que o sucesso desse tipo de medida deve depender de uma série de fatores, como a sua cobertura, os níveis de redução das horas trabalhadas e dos salários, e a duração do programa.

Este artigo tem como objetivo apresentar algumas propostas que têm sido sugeridas em alguns países envolvendo short-time work para manutenção do emprego e da renda durante o cenário

1. DOI: http://dx.doi.org/10.38116/bmt69/politicaemfoco1

2. Técnico de planejamento e pesquisa na Diretoria de Estudos e Políticas Sociais (Disoc) do Ipea.E-mail: <mauricio.reis@ipea.gov.br>.

3. Técnica de planejamento e pesquisa na Disoc/lpea.E-mail: <joana.costa@ipea.gov.br>. 
pandêmico da Covid-19. Além disso, são descritos alguns resultados de políticas semelhantes a partir das análises de experiências implantadas durante a crise financeira de 2008-2009.

\section{EXPERIÊNCIAS INTERNACIONAIS NA CRISE DE 2020}

Na página da OIT $^{4}$ podem ser encontradas as descriçôes dos programas adotados em cada país para o enfrentamento da crise resultante da Covid-19. Entre essas medidas, aparecem citadas diversas propostas de short-time work. A intenção aqui não é fazer uma revisão exaustiva desses programas, mas apenas apresentar alguns exemplos das características desses em diferentes países. O quadro 1 apresenta esses resultados.

QUADRO 1

Características do programa short-time work em alguns países

\begin{tabular}{|c|c|}
\hline País & Características do programa \\
\hline Alemanha & $\begin{array}{l}\text { As condições para receber os benefícios provenientes do programa de short-time work foram } \\
\text { alteradas para permitir a inclusão de trabalhadores temporários e instituir a compensação to- } \\
\text { tal das contribuições sociais efetuadas pelos empregadores, assim como aumentar os valores } \\
\text { dos benefícios. Os benefícios são pagos pelo empregador, que é compensado pelo governo. }\end{array}$ \\
\hline Bélgica & $\begin{array}{l}\text { A elegibilidade para o programa de desemprego temporário foi ampliada, assim como o valor } \\
\text { do benefício teve aumento de } 65 \% \text { para } 70 \% \text { do salário do trabalhador, com um adicional de } \\
€ 5,63 \text { por dia. Foi concedido um auxílio antecipado de } € 1.450 \text { para as pessoas que deram } \\
\text { entrada no programa. }\end{array}$ \\
\hline Canadá & $\begin{array}{l}0 \text { acordo para vigência do programa foi estendido e a participação das empresas foi ampliada, } \\
\text { flexibilizando os critérios de exigibilidade. Também foram ampliados os critérios de elegibili- } \\
\text { dade para os trabalhadores. }\end{array}$ \\
\hline Dinamarca & $\begin{array}{l}\text { O sistema de short-time work foi flexibilizado e passou a disponibilizar mais recursos. Para fir- } \\
\text { mas que sofreram reduções acentuadas na demanda, os trabalhadores podem ser mandados } \\
\text { para casa com o governo cobrindo } 75 \% \text { do salário, até um máximo correspondente a cerca de } \\
€ 4 \text { mil. As firmas devem pagar os } 25 \% \text { restantes do salário do trabalhador, que, por sua vez, } \\
\text { deve contribuir com cinco dias das suas férias anuais. }\end{array}$ \\
\hline Espanha & $\begin{array}{l}\text { O governo facilitou o acesso a um programa por meio do qual podem ser estabelecidas suspensões } \\
\text { de contrato ou reduções nas horas trabalhadas, e os trabalhadores têm direito ao seguro-desem- } \\
\text { prego sem que isso prejudique os seus direitos no futuro. As firmas com menos de cinquenta em- } \\
\text { pregados tiveram os seus pagamentos de contribuições sociais suspensas, enquanto para as demais } \\
\text { o pagamento foi estabelecido em } 25 \% \text {, sem que isso acarrete prejuízos para os trabalhadores. }\end{array}$ \\
\hline França & $\begin{array}{l}\text { Mesmo com reduções nas horas trabalhadas, os salários brutos devem ser mantidos em } 70 \% \\
\text { do valor anterior, o que corresponde a cerca de } 84 \% \text { do salário líquido. Para os trabalhadores } \\
\text { que recebem salário mínimo, a compensação deve ser de } 100 \% \text { do salário. }\end{array}$ \\
\hline Itália & $\begin{array}{l}\text { Durante o período de redução das atividades, os trabalhadores recebem do governo uma } \\
\text { quantia equivalente a } 80 \% \text { dos seus salários brutos. } 0 \text { programa cobre todos os setores, com } \\
\text { exceção do trabalho doméstico. }\end{array}$ \\
\hline Nova Zelândia & $\begin{array}{l}0 \text { governo disponibilizou recursos para que os trabalhadores mantenham pelo menos } 80 \% \\
\text { dos seus salários anteriores à crise da Covid- } 19 \text {. }\end{array}$ \\
\hline Reino Unido & $\begin{array}{l}\text { Os trabalhadores impossibilitados de realizar as suas tarefas podem receber } 80 \% \text { das suas } \\
\text { remunerações anteriores até um valor máximo de } £ 2,5 \text { mil por mês. Em maio de } 2020 \text {, esse } \\
\text { programa foi estendido até outubro do mesmo ano. }\end{array}$ \\
\hline
\end{tabular}

4. Disponível em: <https://bit.ly/20mLfHe> . Acesso em: 17 jun. 2020. 
Fonte: OIT. Disponível em: <https://bit.ly/2OmLfHe>. Acesso em: 17 jun. 2020.

Percebe-se que os programas adotados têm algumas características comuns. Em geral, procura-se oferecer elegibilidade para um contingente bem amplo dos trabalhadores. Nos países em que programas de short-time work já estavam disponíveis, a cobertura foi ampliada em muitos casos. Outra preocupação foi com a manutenção da renda dos trabalhadores, para que seja mantida próxima do valor anterior à crise. Muitos países ampliaram os valores dos benefícios nas situaçôes em que esse tipo de programa já estava disponível. Nota-se também uma preocupação com a renda dos trabalhadores mais vulneráveis.

\section{EXPERIÊNCIA BRASILEIRA NA CRISE DE 2020}

O Programa Emergencial de Manutenção do Emprego e da Renda estabelecido pela Medida Provisória (MP) no 936/2020 insere-se nesse contexto de preservar os vínculos trabalhistas formais e garantir a renda dos trabalhadores em meio à crise provocada pela pandemia da Covid-19. Essa medida estabelece a possibilidade de reduçáo da jornada de trabalho ou de suspensão temporária do contrato de trabalho para os empregados com carteira assinada do setor privado, tendo como compensação o pagamento de um benefício emergencial ao trabalhador (Brasil, 2020).

O programa permite que, por meio de acordo individual, ${ }^{5}$ a jornada de trabalho seja reduzida nos percentuais de $25 \%, 50 \%$ e $70 \%$ por até noventa dias, ou que o contrato seja temporariamente suspenso por até sessenta dias. Esse acordo individual poderá ser celebrado com empregados que tenham remuneraçáo inferior a $\mathrm{R} \$ 3.135,00$ ou superior (ou igual) a duas vezes o limite máximo dos benefícios do Regime Geral de Previdência Social. ${ }^{6}$ Para os empregados com salários dentro desse intervalo, ${ }^{7}$ é necessário um acordo coletivo ou convenção para que seja estabelecida a suspensáo do contrato ou a redução da jornada, exceto se a redução for de $25 \% .{ }^{8}$ Durante esse período de suspensão ou redução, os trabalhadores receberão um benefício emergencial do governo cuja base de cálculo é o seguro-desemprego. Após o prazo estipulado, a jornada e o contrato de trabalho deveráo ser restabelecidos e mantidos por um tempo equivalente ao de redução ou suspensão (período de garantia provisória). ${ }^{9}$

No caso da redução da jornada em 25\%, 50\% ou 70\%, o empregador deve manter o salário horário, e, assim, pagar pela jornada que for mantida. Nessas situaçóes, o valor do benefício proporcionado pelo governo corresponderá ao percentual de redução da jornada

5. Outros percentuais podem ser estabelecidos somente por meio de acordos coletivos, e a regra para pagamento do benefício emergencial variará em cada caso.

6. Além da remuneração igual ou superior a duas vezes o limite máximo dos benefícios do Regime Geral de Previdência Social, este empregado deve possuir o nível superior completo.

7. Considerando o valor atual do salário mínimo, esse intervalo corresponde de 3 salários mínimos $(R \$ 3.135,00)$ a 11,67 salários mínimos (R\$12.202,12).

8. Isto é, a redução da jornada em $25 \%$ pode ser feita por acordo individual independentemente do patamar salarial do empregado. 9. Assim, se houver dispensa sem justa causa dos trabalhadores durante o período de garantia provisória, o empregador terá que indenizar no valor equivalente entre $50 \%$ a $100 \%$ do salário a que o trabalhador teria direito durante o período de garantia provisória (além das multas rescisórias que estiverem em vigor). 
multiplicado pelo valor de seguro-desemprego que o empregado teria direito em caso de demissão. ${ }^{10} \mathrm{O}$ salário recebido pelo trabalhador somado ao valor do benefício não poderá ser inferior ao correspondente a um salário mínimo.

No caso da suspensão do contrato de trabalho, o empregador deverá pagar como ajuda compensatória mensal (com natureza indenizatória) o equivalente a $30 \%$ do salário do empregado, se a receita bruta da empresa tiver sido superior a $\mathrm{R} \$ 4,8$ milhóes em 2019. Este valor será complementado pelo benefício emergencial equivalente a $70 \%$ do seguro-desemprego devido em caso de desligamento. Para trabalhadores de empresas com receita bruta inferior a $\mathrm{R} \$$ 4,8 milhóes em 2019, a suspensão do contrato de trabalho implicará nenhum pagamento por parte do empregador e no recebimento de um benefício emergencial equivalente ao valor integral do seguro-desemprego.

O cálculo do seguro-desemprego corresponde a $80 \%$ da média dos três últimos salários, caso esta média seja inferior a $\mathrm{R} \$ 1.599,61$. Caso a média dos três últimos salários esteja entre $\mathrm{R} \$ 1.599,62$ e R \$ 2.666,29, o valor da média subtraída de R \$ 1.599,61 deve ser multiplicado por $50 \%$ e somado a $R \$ 1.279,69$. Se a média for superior a $\mathrm{R} \$ 2.666,29$, o seguro-desemprego será $\mathrm{R} \$ 1.813,03$. Acrescenta-se, ainda, que o valor do seguro-desemprego não pode ser inferior ao salário mínimo. Para os casos de contrato de trabalho intermitente, a MP no 936/2020 estabelece o pagamento de três parcelas fixas de $\mathrm{R} \$ 600,00$ (independentemente da quantidade de contratos intermitentes) a semelhança do auxílio emergencial recebido pelos trabalhadores informais de acordo com a Lei no 13.982/2020.

Apesar de o benefício emergencial ter como base de cálculo o seguro-desemprego, o mesmo será pago ao empregado independentemente do cumprimento de período aquisitivo, ou do tempo de vínculo empregatício, ou do número de salários recebidos. A ausência dessas restriçôes é relevante, já que a cobertura efetiva do seguro-desemprego é baixa (Amorim e Bilo, 2019), e aplicá-las ao benefício emergencial implicaria restringir o acesso.

Embora tenha como intenção evitar demissóes durante esse período de crise, a principal crítica à MP nº 936/2020 refere-se à sua capacidade em garantir os rendimentos dos trabalhadores afetados. Se, por um lado, esse pacote de medidas tem sido elogiado por contribuir para a manutenção de vínculos empregatícios e de postos de trabalho, por outro lado, a MP no 936/2020 tem sido criticada por não garantir plenamente o salário dos trabalhadores. No entanto, diversos programas de apoio aos empregos em países da OCDE também não garantem integralmente o valor dos salários dos empregados. No Brasil, é importante a característica de assegurar uma proporção maior da renda aos que recebem menos. Porém, chama a atenção o fato de que, para empregados com salários de três salários mínimos, a redução da jornada em $70 \%$ resultaria em uma taxa de reposição de $70 \%$, e a suspensão temporária, em $58 \%$ (Welle et al., 2020; Costa e Reis, 2020).

10. No caso de acordo ou convenção coletiva, o benefício não será pago no caso de reduções de jornada inferiores a 25\%, equivalerá a $25 \%$ da base de cálculo para reduções de jornada entre $25 \%$ e $50 \%$, e corresponderá a $70 \%$ para reduções acima de $70 \%$. 


\section{EXPERIÊNCIAS INTERNACIONAIS NA CRISE DE 2008-2009}

A crise financeira de 2008-2009 motivou a adoção de medidas de short-time work por parte de vários países como forma de manter os empregos e os salários dos trabalhadores. Hijzen e Venn (2011) mostram que medidas desse tipo foram adotadas ou passaram por ajustes em 22 países da OCDE durante esse período de crise. As evidências empíricas têm mostrado que os seus efeitos foram positivos, mas também foram identificados alguns pontos que parecem relevantes para que esses programas tenham sucesso.

De acordo com Hijzen e Venn (2011), muitos países da OCDE já tinham programas de short-time work, enquanto outros implantaram medidas desse tipo durante a crise de 2008-2009. No primeiro grupo, muitos dos programas foram reformulados com a ampliação da cobertura, o aumento dos benefícios e a redução nas exigências para participação de trabalhadores e firmas. Para esses autores, programas de short-time work tiveram importante impacto na preservação dos empregos. Conclusóes semelhantes são apresentadas por Hijzen e Martin (2013) e Cahuc, Kramarz e Nevoux (2018).

Alguns pontos referentes ao melhor desenho de programas de short-time work também têm sido discutidos na literatura. $\mathrm{O}$ uso continuado do programa após o período de crise mais intensa foi apontado por Hijzen e Martin (2013) como um fator prejudicial para o bom desempenho do programa nos países da OCDE. Segundo esses autores, passado o período de crise, o programa pode limitar a expansão do emprego na recuperação, com as firmas permanecendo na situação em que os seus custos são financiados pelo governo. Cahuc, Kramarz e Nevoux (2018) destacam que os benefícios do programa foram limitados pela participação de firmas que reduziram horas de empregos com baixo risco de serem destruídos durante a crise. Ainda de acordo com esses autores, a eficiência do programa deve ser maior se este se concentrar em firmas que tiveram grandes reduçôes na receita.

\section{CONCLUSÕES}

Programas de short-time work oferecem uma alternativa importante para o enfrentamento da redução severa nas atividades econômicas como consequência da pandemia da Covid-19. Os trabalhadores se beneficiam da manutenção dos seus empregos e do capital humano específico, assim como das suas rendas. Para as firmas, existe a vantagem de manter os seus trabalhadores e de evitar o recrutamento e treinamento de novos empregados, facilitando a retomada das atividades.

Evidências recentes têm mostrado resultados positivos de short-time work para a manutençáo do emprego na crise da Covid-19. Adams-Prassl et al. (2020) analisam os mercados de trabalho na Alemanha, no Reino Unido e nos Estados Unidos em março e abril de 2020. O fato de a Alemanha ter um programa de short-time work bem estabelecido é apontado como determinante para que as consequências da crise tenham sido menores nesse país. Enquanto no Reino Unido e nos Estados Unidos 15\% e 18\% dos trabalhadores, respectivamente, perderam seus empregos no período de quatro semanas, na Alemanha esse percentual foi de 5\%. 


\section{REFERÊNCIAS}

ADAMS-PRASSL, A. et al. Inequality in the impact of the coronavirus shock: evidence from real time surveys. Bonn: IZA, 2020. (Discussion Paper Series, n. 13183).

AMORIM, B.; BILO, C. Seguro-desemprego ao redor do mundo: uma visão geral. Rio de Janeiro: Ipea, 2019. (Nota Técnica, n. 55).

BRASIL._Medida Provisória no 936, de 1ํ de abril de 2020. Institui o Programa Emergencial de Manutenção do Emprego e da Renda e dispóe sobre medidas trabalhistas complementares para enfrentamento do estado de calamidade pública reconhecido pelo Decreto Legislativo no 6, de 20 de março de 2020, e da emergência de saúde pública de importância internacional decorrente do coronavírus (Covid-19), de que trata a Lei no 13.979 , de 6 de fevereiro de 2020, e dá outras providências. Diário Oficial, p. 1, 1 abr. 2020. Disponível em: <https:// bit.ly/3fqsDC5>. Acesso em: 17 jun. 2020.

CAHUC, P.; KRAMARZ, F.; NEVOUX, S. When short-time work works. [s.l.]: Banque de France, 2018. (Working Paper Series, n. 692).

COSTA, J.; REIS, M. Uma análise da MP no 936/2020 sobre os rendimentos dos trabalhadores e a renda domiciliar per capita. Brasília: Ipea, 2020. (Nota Técnica, n. 71).

GERARD, F; IMBERT, C.; ORKIN, K. Social protection response to the Covid-19 crisis: options for developing countries. Econfip, abr. 2020. Disponível em: <https://bit.ly/3j0KCB1>.

GIUPPONI, G.; LANDAIS, C. Subsidizing labor hoarding in recessions: the employment and welfare effects of short time work. [s.l.]: SSRN, nov. 2018. (CEPR Discussion Paper, n. DP13310). Disponível em: <https://bit.ly/3iXQRFV>.

HIJZEN, A.; MARTIN, S. The role of short-time work schemes during the global financial crisis and early recovery: a cross-country analysis. Bonn: IZA, 2013. (Discussion Paper Series, n. 7291).

HIJZEN, A.; VENN, D. The role of short-time work schemes during the 2008-2009 recession. Paris: OECD, 2011. (OECD Social, Employment and Migration Working Papers, n. 115).

ILO - INTERNATIONAL LABOUR ORGANIZATION. ILO Monitor: Covid-19 and the world of work - updated estimates and analysis. ILO, 7 abr. 2020. Disponível em: <https:// bit.ly/2WfamjH>. Acesso em: 15 abr. 2020.

WELLE, A. et al. Impactos da MP no 936/2020 no rendimento dos trabalhadores e na massa salarial. Campinas: Cecon/Unicamp, abr. 2020. (Nota do Cecon, n. 11). 